\section{Synthesis of brucite from reject brine and its direct carbonation for possible use as construction material}

\author{
R. HAY, I. SINGH, AND K. CELIK*
}

Division of Engineering, New York University Abu Dhabi, Abu Dhabi, P.O. Box 129188, United Arab Emirates (*correspondence: kemal.celik@nyu.edu)

Reactive magnesium oxide (MgO) cement (RMC) has been shown to exhibit a significant mechanical property development under concentrated $\mathrm{CO}_{2}$ curing, attributed to the hydration of $\mathrm{MgO}$ to form brucite and its further reaction with $\mathrm{CO}_{2}$ to form interlocking carbonates of higher unit volume [1]. RMC is conventionally produced for calcination of magnesite $\left(\mathrm{MgCO}_{3}\right)$ at a temperature between $700-1000$ ${ }^{\circ} \mathrm{C}$. Despite limited sequestration of $\mathrm{CO}_{2}$ as a result of carbonation, the environmental benefit of RMC as a construction material is in doubt. The decomposition of $\mathrm{MgCO}_{3}$ alone is more $\mathrm{CO}_{2}$ intensive than that of $\mathrm{CaCO}_{3}$ [2], the main raw material used in the production of ordinary Portland Cement. Together with fuels required for combustion in the calcination process, the total $\mathrm{CO}_{2}$ emission is estimated to be 1.7 tonnes per tonne of RMC [3].

RMC could also be produced from reject brine through precipitation to form brucite and its calcination [4]. This route would eliminate $\mathrm{CO}_{2}$ released from the chemical decomposition of $\mathrm{MgCO}_{3}$ as in the dry route. It has also been shown that supercritical $\mathrm{CO}_{2}\left(\mathrm{scCO}_{2}\right)$ significantly enhanced carbonation and strength development of RCM-based composites [5]. It is hypothesized that $\mathrm{scCO}_{2}$ could be used to directly carbonate brucite. In this study, the synthesis of brucite from reject brine and its direct carbonation were investigated as a more sustainable route in the production and utilization of brucite. Cost-effective $\mathrm{CaO}$ or $\mathrm{Ca}(\mathrm{OH})_{2}$ was used as the precipitation agent at 4 concentration levels (2, 3, 4 and 5 times the saturation limit) to investigate the product yield. The precipitates were filtered and washed with deionized water to removed impurities. The powders were dried in oven at $100{ }^{\circ} \mathrm{C}$ for 12 hours and were allowed to cool in air. Water was then added at a ratio of 0.50 to produce a paste, which was used to prepare $13 \mathrm{~mm}$ pellets under an applied pressure of $5 \mathrm{MPa}$. The pellets were exposed to two carbonation conditions: (i) $20 \% \mathrm{CO}_{2}, 80 \%$ relatively humidity (RH) and $30^{\circ} \mathrm{C}$, and (ii) $\mathrm{ScCO}_{2}$ condition at $8.25 \mathrm{MPa}$ and $35{ }^{\circ} \mathrm{C}$. XRD, TGA, SEM, and nanoindentation were implemented on the samples before and after carbonation.

It was revealed that the yield increased with the content of $\mathrm{Ca}(\mathrm{OH})_{2}$ and the precipitates were composed of $\mathrm{Mg}(\mathrm{OH})_{2}, \mathrm{Ca}(\mathrm{OH})_{2}, \mathrm{CaCO}_{3}$, and other minor impurities. Both $\mathrm{CO}_{2}$ regimes induced carbonation in all the samples with the indentation modulus increased by a factor of 1.1 under $20 \% \mathrm{CO}_{2}$ and 1.6 under $\mathrm{scCO}_{2}$ at the average indentation depth of $500 \mathrm{~nm}$ in samples prepared using 3 times saturation of $\mathrm{Ca}(\mathrm{OH})_{2}$. Samples synthesized with higher $\mathrm{Ca}(\mathrm{OH})_{2}$ content exhibited higher mechanical properties, attributable to observed morphological improvement and matrix densification. TGA results confirmed the formation of carbonates in all samples under $\mathrm{CO}_{2}$ and were used to calculate the carbon sequestration factors. SEM-EDX confirms the incorporation of carbon in the microstructure and the increased presence of rod-like carbonation products of samples under $\mathrm{scCO}_{2}$ (Fig. 1). The findings prove the possibility of direct carbonation and the associated binding action, in addition to the strength development of brucite synthesized from reject brine. Such an innovative solution will eliminate the energy required for calcination and $\mathrm{CO}_{2}$ released from the chemical decomposition of $\mathrm{MagCO}_{3}$ in the production of $\mathrm{RMC}$, paving the way for truly carbon-negative construction material.

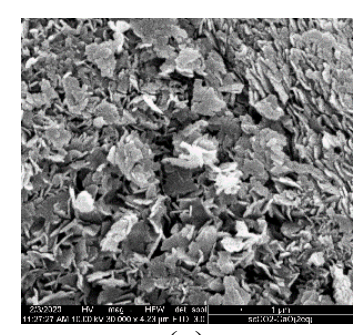

(a)

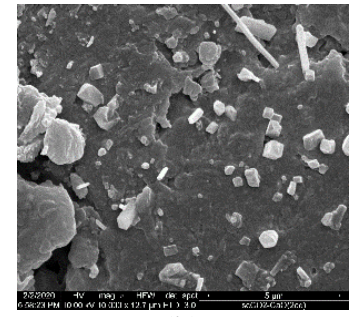

(b)
Figure 1: Microstructure of brucite pellet (a) before and (b) after $\mathrm{scCO}_{2}$ exposure

\section{References}

[1] Dung, N. T., Lesimple, A., Hay, R., Celik, K., \& Unluer, C. (2019). Formation of carbonate phases and their effect on the performance of reactive $\mathrm{MgO}$ cement formulations. Cement and Concrete Research, 125, 105894.

[2] Shen, W., Cao, L., Li, Q., Wen, Z., Wang, J., Liu, Y., Dong, R., Tan, Y., \& Chen, R. (2016). Is magnesia cement low carbon? Life cycle carbon footprint comparing with Portland cement. Journal of Cleaner Production, 131, 20-27.

[3] Ruan, S., \& Unluer, C. (2016). Comparative life cycle assessment of reactive $\mathrm{MgO}$ and Portland cement production. Journal of Cleaner Production, 137, 258273.

[4] Walling, S. A., \& Provis, J. L. (2016). MagnesiaBased Cements: A Journey of 150 Years, and Cements for the Future? Chemical reviews, 116(7), 4170-4204.

[5] Hay, R., \& Celik, K. (2020). Accelerated carbonation of reactive magnesium oxide cement (RMC)-based composite with supercritical carbon dioxide ( $\mathrm{scCO} 2)$. Journal of Cleaner Production, 248, 119282. doi:https://doi.org/10.1016/j.jclepro.2019.119282 